\title{
CORRELAÇÃO ENTRE NÍVEIS SANGUÍNEOS DE COLESTEROL HDL E DESCRITORES CLÍNICOS PERIODONTAIS EM INDIVÍDUOS COM SÍNDROME METABÓLICA.
}

\author{
Beatriz Santos Serra Teixeira ${ }^{1}$; Isaac Suzart Gomes Filho² ${ }^{2}$ Patrícia Mares de \\ Miranda $^{3}$ e Soraya Castro Trindade ${ }^{4}$.
}

1. Bolsista PROBIC/UEFS, Graduando em Odontologia, Universidade Estadual de Feira de Santana biasst123@gmail.com

2. Orientador, Departamento de Saúde, Universidade Estadual de Feira de Santana: isuzart@gmail.com

3. Participante do projeto, Programa de Pós-Graduação em Imunologia, Universidade Federal da Bahia. paty_mmiranda@hotmail.com

4. Coordenadora do NUPPIM, Departamento de Saúde, Universidade Estadual de Feira de Santana: soraya.castrotrindade@gmail.com

PALAVRAS-CHAVE: Periodontite, doença cardiovascular, síndrome metabólica.

\section{INTRODUÇÃOO}

A síndrome metabólica (SM) tem despertado interesse no campo da saúde, vez que é apontada como o fator preponderante para a ocorrência de eventos cardiovasculares. É representada por um conjunto de fatores de risco, normalmente, relacionados à resistência à insulina e deposição de gordura. (MCLELLAN et al, 2007). O diagnóstico é estabelecido quando o indivíduo apresenta pelo menos três das seguintes alterações metabólicas: distúrbios no metabolismo da glicose, obesidade (especialmente a abdominal), hipertensão arterial e hipertrigliceridemia e/ou baixos níveis de HDL colesterol (HDL-c). Normalmente estas se manifestam juntas e são fatores de risco para a doença coronariana em especial, a aterosclerose. (KORHONEN et al., 2011).

Algumas condições inflamatórias à distância têm sido associadas à SM, a exemplo da periodontite. A plausibilidade biológica para esta associação está baseada na migração das bactérias bucais e seus subprodutos para corrente circulatória, com disseminação sistêmica de mediadores inflamatórios de origem local, como interleucinas (IL-6, IL-1 $\beta$,) e TNF (HAN et al, 2012), o que pode estabelecer um quadro inflamatório sistêmico crônico (HAN et al, 2012; FUKUI et al, 2012). Outra possibilidade investigada é a de que a periodontite poderia estimular os hepatócitos a produzir citocinas em maiores quantidades, como à proteína C-reativa (PCR) (NISHIMURA et al, 2001; D'AIUTO et al, 2004). Seria dessa forma que o aumento da produção de metabólitos circulantes estaria relacionado ao processo causal da SM (HAN et al, 2012; FUKUI et al, 2012).

Diante da possibilidade das doenças periodontais poderem contribuir para o estado inflamatório sistêmico do indivíduo e levar a alterações no metabolismo lipídico sérico (MACHADO et al., 2005), o presente trabalho busca investigar a correlação dos níveis sanguíneos de colesterol HDL e a condição clínica periodontal, determinada por meio dos descritores clínicos periodontais. 


\section{MATERIAL E MÉTODOS}

Estudo desenvolvido com voluntários com SM, examinados no Centro de Atenção ao Diabético e Hipertenso (CADH) do município de Feira de Santana. O diagnóstico de presença ou ausência de síndrome metabólica foi realizado segundo os critérios da Federação Internacional de Diabetes (do inglês, IDF), adaptados para a população brasileira. Foram classificados como casos de SM todos os participantes que combinaram alteração de pelo menos três dos seguintes parâmetros: obesidade abdominal por meio da circunferência abdominal; HDL colesterol; pressão arterial e glicemia de jejum.

Os descritores clínicos periodontais foram obtidos por examinadores previamente treinados, com o emprego de sonda milimetrada do tipo Williams (HUFRIEDY, Chicago, USA), registrados em ficha clínica e, posteriormente, em um banco de dados. Todas as observações foram obtidas em seis diferentes locais para cada unidade dentária (disto-vestibular, médio-vestibular, mésio-vestibular, disto-lingual, médio-lingual, mésio-lingual), exceto para o índice de placa visível que é avaliado apenas em 4 locais (mesial, distal, vestibular e lingual). Os índices avaliados foram: profundidade à sondagem (PS), índice de sangramento à sondagem (SS), índice de placa visível (IP) e nível de inserção clínica (NIC).

Inicialmente, os dados obtidos foram analisados quanto a sua distribuição com o emprego do teste Kolmogorov-Smirnov. Como não foi observada distribuição normal, foi utilizado o teste não paramétrico coeficiente de correlação de Spearman, cuja magnitude é expressa em $r_{s}$. As correlações foram consideradas estatisticamente significantes ao nível de $95 \%(\mathrm{p} \leq 0,05)$.

\section{RESULTADOS E DISCUSSÃO}

Foram examinados 317 voluntários diagnosticados com SM, com média de idade de 56,47 (DP $\pm 12,26$ ) anos e mediana de 57 (IQ: 48-65) anos. A idade mínima foi de 27 e a idade máxima foi de 87 anos. Quanto ao sexo dos participantes, 103 (32,5\%) eram do sexo masculino e $214(67,5 \%)$ do sexo feminino. Estes dados corroboram um estudo prévio realizado em uma área rural do Semiárido Baiano revelou uma prevalência maior de SM entre mulheres com idade $\geq 45$ anos (Oliveira, Souza e Lima, 2006). Outro fator para uma maior frequência de pessoas do sexo feminino pode ser o fato das mulheres buscarem mais os serviços de saúde em relação aos homens.

$\mathrm{Na}$ análise dos descritores clínicos periodontais, foi observado que a mediana da PS foi de 2,23 (IQ:1,8-2,8) mm e do NIC foi de 3,4 (2,6-4,4) mm. Além disso, a mediana do percentual de sítios por indivíduos com PS $\geq 4 \mathrm{~mm}$ foi de 3\% (IQ:0-6\%), com SS foi de 31,4\% (IQ:12,9-58,6\%), com IP foi de 28,6\% (IQ:5-66,8\%), com NIC de 1-2mm foi de 0 (IQ:0-3\%), com NIC de 3-4mm foi de 5\% (IQ:2-9\%) e com NIC de $\geq 5 \mathrm{~mm}$ foi de $5 \%(3-9 \%)$.

Foi observada uma discreta correlação negativa entre a concentração plasmática de colesterol HDL e o percentual de sítios com nível de inserção clínica $\geq 5 \mathrm{~mm}$ $(\mathrm{p}=0,001$; Rs=-0,110), como pode ser observado na figura 1. Quando os NIC mensurados foram nas faixas de 3-4mm (Figura 2) e de 1-2mm (Figura 3), a houve 
discreta correlação positiva $(p=0,030 ; \quad R s=0,074$ e $\quad p=0,010 ; \quad R s=0,087$, respectivamente).

\section{Colesterol HDLX NIC $\geq 5 \mathrm{~mm}$}

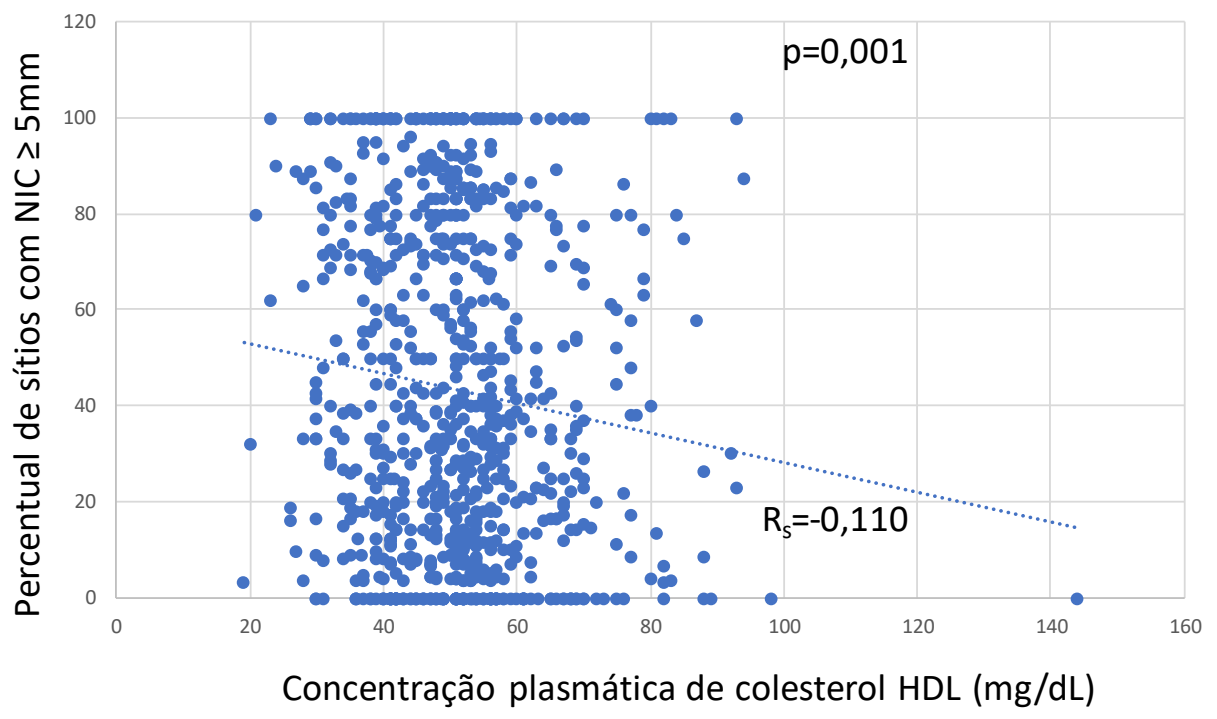

Figura 1: Correlação entre a concentração plasmática de colesterol HDL (mg/dL) e o percentual de sítios com nível de inserção clínica (NIC) $\geq 5 \mathrm{~mm}$. Rs: coeficiente de correlação de Spearman; $\mathrm{p} \leq 0,05)$.

\section{Colesterol HDL X NIC=3-4mm}

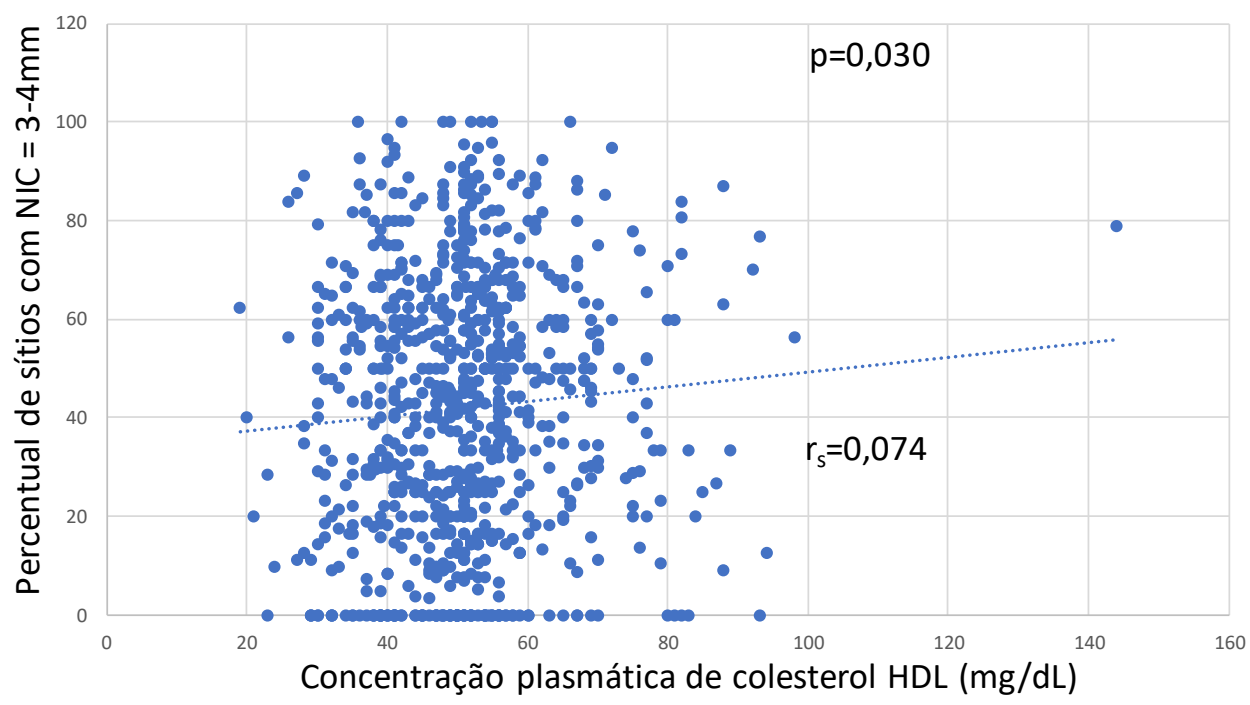

Figura 2: Correlação entre a concentração plasmática de colesterol HDL (mg/dL) e o percentual de sítios com nível de inserção clínica (NIC) de 3 ou 4 mm. Rs: coeficiente de correlação de Spearman; $\mathrm{p} \leq 0,05)$. 


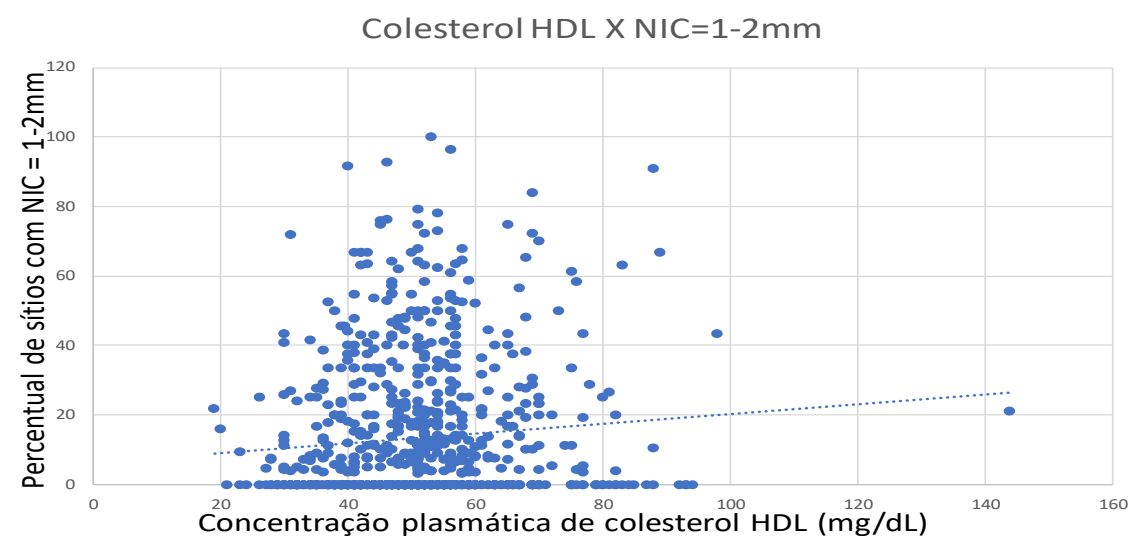

Figura 3: Correlação entre a concentração plasmática de colesterol HDL (mg/dL) e o percentual de sítios com nível de inserção clínica (NIC) de 1-2 mm. Rs: coeficiente de correlação de Spearman; $\mathrm{p} \leq 0,05)$.

A literatura ainda é controversa acerca da relação entre a periodontite e os níveis de colesterol HDL, principalmente porque a maioria deles não avaliou o HDL como variável principal. Mas esta relação pode ser devida à presença de microrganismos gram-negativos no biofilme subgengival, que podem induzir uma resposta hiperinflamatória local, com destruição dos tecidos periodontais, que pode disseminar, levando a um estado inflamatório sistêmico (MACHADO et al., 2011).

\section{CONCLUSÃO}

A perda de inserção clínica periodontal parece estar relacionada aos níveis plasmáticos de colesterol HDL em indivíduos com síndrome metabólica.

\section{REFERÊNCIAS}

D'AIUTO, F.; READY, D.; TONETTI, M. S. Periodontal disease and C-reative protein- associated cardiovascular risk. Journal of Periodontal Research, v.39, p.236241, 2004.

FUKUI, N. et al., Periodontal Status and Metabolic Syndrome in Middle-Aged Japanese. Journal of Periodontology, v. 83, p. 1363-1371, 2012.

HAN, D. H. et al. Periodontitis could be related factors on metabolic syndrome among Koreans: a case-controlstudy. J Clin Periodontol, v. 39, p. 30-37, 2012.

MACHADO, E. et al. Obesidade como fator de risco à periodontite: é possível? Revista Gaúcha de Odontologia, v. 59, p. 45-50, 2011.

McLELLAN, K.C.P. et al. Diabetes mellitus do tipo 2, síndrome metabólica e modificação no estilo de vida. Rev. Nutr, v.20, n.5, p.515-524, 2007.

NISHIMURA, F. et al., Periodontal inflammation and insulin resistance - lessons from obesity. J Dent Res, v. 80, p. 1690-4, 2001.

OLIVEIRA, E.P.; SOUZA, M.L.; LIMA, M.D. Prevalence of metabolic syndrome in a semi-arid rural area in Bahia. Arq Bras Endocrinol Metabol, v.31, n.3, p.456-465, 2006.

KORHONEN, S. et al. Serum cholesterol ratios and periodontal infection: results of the Health 2000 Survey. J Clin Periodontol, v.38, n.9, p.787-94, 2011.

MACHADO, A.C.; QUIRINO, M.R.; NASCIMENTO, L.F. Relation between chronic periodontal disease and plasmatic levels of triglycerides, total cholesterol and fractions. Braz Oral Res, v.19, n.4, p.284-9, 2005. 